\title{
A avaliação das aprendizagens no ensino básico portuguễs e o reforço da avaliação sumativa' externa
}

\author{
Carlos Alberto Ferreira"
}

I- A palavra sumativa é aquela escrita em Portugal, com o mesmo significado do termo somativa utilizado no Brasil.

II- Universidade de Trás-os-Montes e Alto Douro, Vila Real, Portugal. Contato: caferreira@utad.pt

\section{Resumo}

A avaliação das aprendizagens, nas últimas décadas, tem sido utilizada pelos Estados economicamente desenvolvidos como um processo de monitorização e de prestação de contas da qualidade da educação escolar promovida, naquilo que se vem designando de processos de accountability. Tal finalidade tem sido concretizada pelo aumento da avaliação sumativa externa, realizada por exames nacionais estandardizados. Os resultados obtidos pelos alunos nessas provas servem de barômetro para aferir e monitorizar essa qualidade educativa, com referência a padrões uniformes, determinados economicamente e que são visíveis em metas oficialmente estabelecidas para a educação escolar. É pela medição do cumprimento dessas metas pelos alunos nos exames nacionais que se processa a aferição e a monitorização por parte dos Estados da qualidade educativa. Não estando Portugal distante dessa influência neoliberal e neoconservadora na educação escolar, o objetivo do presente texto consiste em analisar e refletir sobre as mudanças nas orientações legais para a avaliação das aprendizagens no ensino básico que foram implementadas a partir de 2012 e que têm que ser enquadradas numa ideologia neoliberal mitigada. Esta análise e reflexão incidem sobre os documentos normativos que atualmente regulamentam a avaliação das aprendizagens no ensino básico português e que se traduziram no alargamento dos exames nacionais de português e a matemática aos três ciclos desse nível de ensino e na tendência de valorização dos resultados em detrimento dos processos de aprendizagem.

\section{Palavras-chave}

Monitorização da educação escolar - Avaliação sumativa externa - Exames nacionais. 


\title{
The learning assessment in the Portuguese compulsory education and the reinforcement of the external summative assessment
}

\author{
Carlos Alberto Ferreiral
}

\begin{abstract}
In the last decades, the assessment of learning, has been used by the economically developed states as a process of monitoring and accountability of the quality of school education, which have been called accountability processes. This has been achieved by increasing the external summative assessment by standardized national tests. The results obtained by the students in these tests serve as a barometer to measure and monitor the quality of education, with reference to standards that are uniform, economically determined and visible in certain officially established goals for school education. It is by measuring the achievement of these goals by pupils in national tests that the measurement and monitoring of educational quality by the states is processed. Portugal is not apart from this neoliberal and neoconservative influence on education. Therefore, the objective of this article is to analyze and reflect on the changes in the legal guidelines for the assessment of learning in compulsory education which have been implemented since 2012 and must be framed in a mitigated neoliberal ideology. My analysis and reflection focus on the normative documents which currently regulate the learning assessment in the Portuguese compulsory education and which have resulted in the widening of the national tests in mathematics and Portuguese in the three cycles of this level of education and also in the trend to value the results at the expense of the learning processes.
\end{abstract}

\section{Keywords}

Monitoring of school education - External summative assessment National tests.

I- Universidade de Trás-os-Montes e

Alto Douro, Vila Real, Portugal.

Contato: caferreira@utad.pt 


\section{Introdução}

Desde 1992, no sistema de avaliação das aprendizagens dos alunos no ensino básico português, foi oficialmente decretado que a avaliação formativa constituía a principal modalidade de avaliação nesse nível de ensino. Com essa medida, pretendia-se criar iguais oportunidades nos alunos para o sucesso escolar, uma vez que é a partir das informações recolhidas e analisadas por esse tipo de avaliação que se regula o processo de ensino e de aprendizagem, ajustando-o às necessidades dos diferentes alunos. Numa lógica de democratização da educação escolar, a reprovação era considerada uma decisão que deveria ocorrer, preferencialmente, nos anos terminais de ciclo, porque se deveria dar tempo aos alunos para superarem eventuais dificuldades de aprendizagem ao longo de cada ciclo do ensino básico.

Porém, com a revisão da estrutura curricular do ensino básico português, que foi implementada desde 2012, verificaram-se mudanças quer na concepção de educação e de currículo, quer no sistema de avaliação das aprendizagens dos alunos. Sendo essa revisão da estrutura curricular influenciada por uma ideologia neoliberal e neoconservadora, o currículo passou a centrar-se nas disciplinas nucleares e a avaliação formativa, apesar de prevista, deixou de ser considerada a principal modalidade de avaliação nesse nível de ensino, para passar a ter maior significado a avaliação sumativa, particularmente a externa, realizada por meio de exames nacionais de Português e Matemática elaborados pela administração central.

Foi com o intuito de refletirmos sobre essas mudanças na avaliação dos alunos no ensino básico português que nos propusemos a escrever o presente texto.

Este encontra-se organizado em três pontos essenciais. No primeiro, fazemos uma reflexão teórica sobre o papel desempenhado pelos exames na responsabilização e na prestação de contas das escolas e dos professores pela qualidade da educação escolar. No segundo ponto, aprofundamos as finalidades explícitas e implícitas dos exames nacionais na monitorização da qualidade da educação escolar pelo Estado e no controle do trabalho dos professores e dos alunos. No terceiro ponto, fazemos uma breve análise e reflexão sobre as mudanças na organização curricular do ensino básico português, pormenorizando aquelas referentes à avaliação das aprendizagens, particularmente o reforço dos exames nacionais de Português e Matemática nos três ciclos que estruturam o referido nível de ensino.

\section{A responsabilização e a prestação de contas na educação através dos exames nacionais}

Num mundo globalizado como este em que se vive atualmente, tem-se verificado que as políticas educativas nos diversos países, nas quais a avaliação das aprendizagens dos alunos tem que ser enquadrada e compreendida, são fortemente determinadas por modelos transnacionais, influenciados pelos interesses econômicos dos países capitalistas mais desenvolvidos (AFONSO, 2000; 2011; AMARAL, 2010; PACHECO, 2011). Daí observar-se, cada vez mais, instituições internacionais, como a Organização para a Cooperação e Desenvolvimento Econômico (OCDE) e o Banco Mundial, a exercerem a sua ação na determinação dessas políticas (AMARAL, 2010; PACHECO, 2000). Consequentemente, essas políticas tendem a convergir para a homogeneização da educação e da formação, em vez de para sua adequação à diversidade e à identidade cultural, social e econômica de cada Estado-Nação (AFONSO, 2011; AMARAL, 2010; PACHECO, 2011). Toda essa homogeneização das políticas educativas justifica-se por

as instituições do estado-nação, e o próprio estado, [deverem] ser vistos como sendo essencialmente moldados a um nível 
supranacional através de uma ideologia do mundo dominante (ou Ocidente), e não como criações nacionais autónomas e únicas (DALE, 2004, p. 426-427).

Daí as políticas educativas de vários países convergirem em orientações comuns, que lhes dão caraterísticas semelhantes e nas quais a avaliação das aprendizagens constitui um meio estratégico para a consecução de determinadas intenções que estão subjacentes a essas políticas.

Desde a década de 80 do século XX, a avaliação dos alunos tem servido de forma de legitimação de uma ideologia política de responsabilização e de prestação de contas das escolas, dos professores e dos próprios alunos pela qualidade da educação escolar e, consequentemente, pelo sucesso educativo. Preocupações essas que já vinham da década de 60 do século XX, quando alguns países implementaram medidas de compensação educativa e constataram que as mesmas não estavam a produzir efeitos na melhoria dos resultados dos alunos (AFONSO, 2000). Mas foi com os avanços nas formas de governação capitalistas e com o intuito da competitividade econômica e do desenvolvimento tecnológico que se começou a assistir, inicialmente nos Estados Unidos da América e na Inglaterra, à proliferação de uma ideologia neoliberal e neoconservadora nas políticas educativas de diversos países, com a supremacia de valores como o individualismo, a competitividade, a responsabilização e a privatização (AFONSO, 2000; 2011; SANTOMÉ, 2000; FERREIRA, 2013). Ideologia neoliberal essa que, baseando-se nos pressupostos econômicos do liberalismo, concebe que os indivíduos são proprietários não só dos seus bens materiais mas também das suas próprias capacidades, sendo livres e capazes, ou não, de as pôr em prática numa sociedade com outros indivíduos igualmente livres (AFONSO, 2000). Daí a valorização do mercado, que é considerado uma instituição mais justa e eficiente na distribuição de bens e serviços, e da liberdade de escolha dos indivíduos, procurando-se que o
Estado interfira o menos possível na vida privada, já que esta é da responsabilidade de cada um. Por outro lado, assistimos ao retomar dos valores tradicionais neoconservadores, o que se está a refletir na educação escolar com a valorização das disciplinas e dos conteúdos tradicionais, naquilo que se vem designando back to basics, pois, como afirma Pacheco (2000, p. 15), “do ideário neoliberal constam o carácter, a educação moral e os valores tradicionais”, tendo a escola "a finalidade de consolidar a aquisição de um conhecimento comum [...] correspondente à literacia cultural, ou ao conhecimento básico e elementar tanto cognitivo como moral".

Essa relação entre o mercado e a tradição justifica-se, segundo Pacheco (2000, p. 11), por ambos terem "em comum a ideia de que a responsabilidade pelo estado da economia e da sociedade pertence à escola, sendo colocada no banco dos réus, e jamais às políticas económicas e sociais".

É nesse contexto que o Estado, através da apropriação de modelos de gestão privada para o domínio da educação pública, passa a assumir o papel de avaliador, preocupando-se mais com o controle dos resultados ou dos produtos do sistema educativo do que com os processos de aprendizagem. Esse papel avaliador do Estado é concretizado através da avaliação das aprendizagens dos alunos, na sua função de verificação e de gestão de resultados. Com tal verificação e gestão, o Estado visa a cumprir a máxima com que se regula, que é a de "melhores resultados com menos despesas e meios" (PACHECO, 2000, p. 12). Logo, o discurso da avaliação da qualidade da educação tanto serve para legitimar a intervenção do Estado no controle da educação escolar quanto serve para responsabilizar as escolas, os professores e os alunos pelos resultados obtidos.

Nesse sentido, Pacheco (2012, p. 2) afirma que as políticas educativas, ao estarem ideologicamente dominadas por uma cultura de avaliação relacionada com a prestação de contas, promovem "lógicas do Estado-avaliador e de quase mercado, mediante a promoção da 
qualidade do sistema educativo com base na estandardização de resultados", pois, num mundo globalizado, orientado pelos interesses econômicos dos grupos dominantes e pelos princípios de mercado, a educação é vista como “um negócio que será mais bem administrado e produzirá a excelência escolar se for regulada pelos interesses dos grupos sociais que controlam o mercado" (PACHECO, 2000, p. 10).

$\mathrm{Na}$ procura da competitividade e do crescimento econômico por parte dos vários países, as políticas educativas orientam-se pelo pressuposto da existência de um Estado mínimo na regulação do mercado e de um Estado máximo na definição e na avaliação dos conteúdos curriculares (PACHECO, 2000; SANTOMÉ, 2000). Isso conduziu a

um aumento do controle da educação pública por parte do Estado, pelo retorno à autoridade e centralidade dos professores (com consequente menosprezo pelas pedagogias construtivistas e não directivas assentes no protagonismo discente), pela revalorização de disciplinas consideradas básicas ou fundamentais no currículo (back to basics), pela introdução de critérios de maior rigor, selectividade e meritocracia, e pela dominância de lógicas de competição, de escolha parental e de mercado educacional tendentes a esbater (ou mesmo acabar com) o monopólio da educação pública estatal. (AFONSO, 2013, p. 272)

0 reforço do controle do poder político sobre a educação escolar e a subjugação da mesma aos princípios de mercado está, como referimos, na origem não apenas de um currículo mínimo com ênfase nas disciplinas nucleares mas também do reforço da avaliação sumativa externa, que são, nessa visão neoliberal, as premissas fundamentais para a competitividade e para o crescimento econômico dos países. Daí a avaliação das aprendizagens dos alunos passar a ser o meio usado pelo poder político para a responsabilização e para a prestação de contas por parte das escolas e dos professores do que, como e por que é feito na educação escolar, naquilo que se tem vindo a afirmar sobre os processos de accountability (AFONSO, 2011; PACHECO, 2000). Apesar de haver diferentes formas de accountability, aqui ela é entendida, em termos latos, como um "ato de justificação e explicação do que é feito, como é feito e por que é feito, [o que] implica, em muitos casos, que se desenvolva alguma forma ou processo de avaliação ou auto-avaliação" (AFONSO, 2011, p. 84), ato esse através do qual essa prestação de contas é realizada, dele decorrendo determinadas consequências.

Esses processos de accountability concretizados pela avaliação das aprendizagens com os exames nacionais estandardizados possibilitam "a divulgação de dados quantificáveis que permitem estabelecer comparações e medições visíveis dos resultados obtidos, facilitando assim a estabilidade da imagem da escola na sociedade" (SANTOMÉ, 2000, p. 75). Gerou-se, por isso, uma regulação da educação escolar e das próprias escolas pelos resultados, mediante procedimentos de competitividade entre elas (PACHECO, 2012), com consequências no seu funcionamento, no trabalho dos professores e dos alunos.

Enquanto instrumentos que medem e classificam os resultados de aprendizagem dos alunos e que possibilitam comparações entre eles, os exames nacionais aferem esses resultados de aprendizagem, que são tomados pelo poder político e pela sociedade em geral como o principal indicador da qualidade educativa. É nessa lógica que se tem vindo a assistir à proliferação de exames nacionais em diversos países e à preocupação com a participação nas avaliações internacionais, nomeadamente no Programme for International Student Assessment (PISA), no sentido da medição e da comparação dos desempenhos dos alunos em Língua Materna, Matemática e Ciências. Também é das avaliações externas por exames nacionais estandardizados que resultam os rankings de escolas, estabelecidos em função dos resultados dos alunos de cada escola nesses exames, no sentido de as responsabilizar pelo 
sucesso educativo dos seus estudantes e pela qualidade da educação promovida. Todos esses mecanismos de accountability baseados nos exames e nos rankings de escolas são "indutores de formas autoritárias de prestação de contas e de responsabilização das instituições, organizações e indivíduos" (AFONSO, 2013, p. 272), com consequências para o seu funcionamento.

Esse discurso político-educativo de influência neoliberal, que usa a avaliação das aprendizagens como mecanismo de controle de resultados, de prestação de contas e de responsabilização, tem vindo a legitimar-se e a ser consensualmente aceito pela sociedade. Para isso, têm contribuído os seguintes fatores mencionados por Afonso (2011): a crise da escola que usa métodos de ensino menos diretivos, visível pelo fato de os resultados dos alunos nos exames e nas provas internacionais ficarem aquém do desejado; a emergência neoliberal e neoconservadora de criação de mercados na educação, que possibilitaram a escolha por parte das famílias em função dos rankings de escolas anualmente publicados; o reforço do controle da educação escolar pelo Estado, com a diminuição curricular e com a defınição mais apertada de objetivos educacionais; a racionalização de custos e de investimentos públicos pelos Estados-providência, com a consequente corresponsabilização da sociedade civil pela educação escolar; o fato de a avaliação por testes e exames nacionais e internacionais ter se tornado meio privilegiado de accountability.

Nesse contexto, em Portugal, a revisão da estrutura curricular dos ensinos básico e secundário realizada em 2012 (PORTUGAL, DECRETO-LEI No 139/2012, DE 5 DE JULHO), espelha essa tendência neoliberal e neoconservadora na educação. Tal influência é visível na redução da oferta de disciplinas nesses dois níveis de ensino, no aumento da carga horária de Português e de Matemática e na introdução de exames nacionais estandardizados desde o primeiro ciclo do enino básico, como analisaremos mais à frente de forma mais detalhada, para além daqueles que existem no ensino secundário.

\section{A avaliação dos alunos por exames estandardizados:}

finalidades explícitas e implícitas

$\mathrm{Na}$ procura de equidade, justiça e rigor na medição das aprendizagens dos alunos, o exame começou a ser utilizado com uma finalidade avaliativa na segunda metade do século XVIII e generalizou-se ao longo do século XIX (BONNIOL; VIAL, 1997). Dada a tradição desse instrumento na avaliação das aprendizagens, foi-se criando, na sociedade, nos decisores políticos e no meio educativo em geral, a crença de que os exames e os testes escritos proporcionam uma avaliação mais rigorosa, mais justa e mais equitativa, porque medem resultados de aprendizagem e hierarquizam os alunos em função do seu mérito. Por essa razão, não é de estranhar o enraizamento de uma concepção de avaliação da aprendizagem como medição e classificação, essencialmente de conhecimentos e de certas capacidades cognitivas, que são aquelas aprendizagens que os testes e os exames escritos possibilitam avaliar (FERNANDES, 2005; FERREIRA, 2006).

Apesar dessa perspectiva de avaliação ter sido teoricamente alargada a partir da década de 60 do século XX, nomeadamente com o aparecimento da avaliação formativa e da diagnóstica, nas últimas décadas, tem vindo a ser retomada e reforçada no contexto da sociedade e das políticas educativas de alguns países mais desenvolvidos economicamente. Procurando-se que a educação escolar dê resposta aos interesses econômicos e de mercado, a influência da ideologia neoliberal e neoconservadora nas políticas educativas tem originado o reforço do controle da educação escolar por parte do poder político e dos grupos sociais e econômicos dominantes. Tal reforço conduz à responsabilização e à prestação de contas das escolas e dos professores pela qualidade educativa e pelo sucesso escolar, através do maior controle dos resultados dos alunos, que são aferidos pelos exames nacionais estandardizados (AFONSO, 2011; BONAMINO; 
SOUSA, 2012; PACHECO, 2011). Esses exames podem ser entendidos como

o conjunto de provas de avaliação externa de larga escala, provas essas padronizadas, desenvolvidas e aplicadas por entidades ao nível central da administração educativa (externas às escolas) que obedecem a procedimentos comuns de aplicação e classificação (sendo esta realizada em contexto de total anonimato) e que têm implicações na progressão dos alunos, na certificação e/ou na sua seleção para acesso a outros níveis de ensino. (SOUSA, 2012, p. 42).

ou para acesso ao mercado de trabalho.

Trata-se de provas que têm como intenção medir o cumprimento, pelos alunos, das metas de aprendizagem ou curriculares estabelecidas pelo poder político para a educação escolar. Metas essas que são delineadas em função das exigências da sociedade e dos interesses dos grupos econômicos dominantes e que condicionam o trabalho realizado pelos professores e pelos alunos (FERREIRA, 2013).

Constituindo a principal orientação para o processo educativo e para a avaliação dos alunos, as metas de aprendizagem são

uma faceta visível da política de prestação de contas - em que o resultado vale mais que o processo e onde os resultados da aprendizagem, operacionalizáveis em metas de aprendizagem, representam um regresso aos objetivos [...] - bem como faz[em] parte de um processo de valorização social da educação e formação, essencialmente na perspetiva da teoria do capital humano. (PACHECO, 2011, p. 86).

Ao indicarem as aprendizagens formais quetodos os alunos têm que realizar para poderem obter diplomas, as metas de aprendizagem, formuladas em termos de objetivos a serem cumpridos, traduzem as normas de excelência de uma cultura dominante, constituídas pelos conhecimentos, competências e formas de ser e de estar valorizados socialmente e pelo mercado de trabalho (PERRENOUD, 1998).

A maior parte dessas aprendizagens são verificadas através dos exames nacionais estandardizados, que as aferem e as classificam. Daí esses resultados constituírem, para o Estado e para a sociedade em geral, o principal indicador da qualidade educativa e do trabalho desenvolvido pelos professores e pelos alunos nas escolas. É nesse sentido que Almeida afırma que

a avaliação de conhecimentos ao serviço do sistema educativo e da sociedade tem o mérito de quantificar o que o aluno aprendeu e também como o professor, a escola e o sistema educativo cumprem a sua função social de preparar as camadas populacionais mais jovens, atingindo os objetivos fixados pelo sistema educativo (2012, p. 77). Os resultados obtidos pelos alunos de cada escola, para além de terem influência no seu percurso escolar ou de vida, são determinantes da imagem socialmente criada da escola. Imagem essa que tem consequências no seu funcionamento, no exercício da docência e na avaliação de desempenho dos docentes, pois, como refere Afonso (2011, p. 88), num sistema de accountability, os exames nacionais permitem "mensurar e codificar padrões de resultados e prever determinadas consequências quando se atingem ou não esses resultados". Isto porque os exames são usados para controlar o nível de desempenho dos alunos, para avaliar a qualidade do sistema educativo, para credibilizar socialmente os diplomas, para contribuir para mudanças no currículo que induzam melhorias na qualidade do ensino e das aprendizagens e para o reforço da confiança social do próprio sistema educativo. (FERNANDES, 2007).

Daí que, nos últimos tempos, se tenha vindo a verificar um reforço da avaliação por 
exames escritos nacionais em vários países desenvolvidos economicamente, na medida em que eles: tornam mais fácil e supostamente mais objetiva e rigorosa a avaliação das metas de aprendizagem; são práticos e consistentes com as expectativas de pais e de alunos; indicam ao professor o que é importante ensinar e ao aluno o que é importante aprender; certificam as aprendizagens dos alunos, que são exigidas social e economicamente; são um mecanismo de controle do sistema educativo, com repercussões no currículo, no funcionamento das escolas e no exercício profissional dos docentes (FERREIRA, 2013; LAVEAULT; GRÉGOIRE, 2002; VALADARES; GRAÇA, 1998).

Sendo instrumentos de avaliação planejados e usados pela administração educativa central, no final do processo de ensino e de aprendizagem, para medir os resultados dos alunos e para controlar a qualidade do sistema educativo em função de padrões uniformes, é com os exames que são certificados os conhecimentos e as capacidades cognitivas valorizados pela sociedade e pelo mercado de trabalho (FERREIRA, 2006). Também é por esse meio que a escola seleciona os alunos mais capazes, dando à sociedade e aos pais/encarregados de educação garantias de que os alunos realizaram, ou não, as aprendizagens social e economicamente exigidas, isto é, que eles são, ou não, detentores das normas de excelência que estão implícitas nos programas e nas metas de aprendizagem formalmente instituídos (PERRENOUD, 1998).

\section{A avaliação das aprendizagens no ensino básico português}

A avaliação das aprendizagens no ensino básico português é, desde o ano letivo de 2012/2013, regulamentada pelo Decreto-Lei $n^{\circ}$ 139/2012, de 5 de julho. Esse documento normativo concretizou, como já referimos atrás, a "revisão da estrutura curricular" dos ensinos básico e secundário portugueses, com alterações nas matrizes curriculares e nas prescrições para a avaliação das aprendizagens dos alunos.
Uma breve referência à nova organização curricular do ensino básico

0 ensino básico constitui o primeiro nível de ensino de frequência obrigatória em Portugal, destinado a crianças/jovens dos seis aos quinze anos de idade. Esse nível de ensino está estruturado em três ciclos (PORTUGAL, LEI No 46/86, DE 14 DE OUTUBR0): o primeiro deles, com quatro anos de escolaridade, é da responsabilidade de um único professor, que leciona as várias áreas curriculares que estruturam o plano curricular do referido ciclo de ensino (PEREIRA, 2008); o segundo ciclo, com o quinto e sexto anos de escolaridade, está organizado por áreas disciplinares, que agrupam, cada uma delas, duas ou mais disciplinas, que são lecionadas preferencialmente por um professor por área disciplinar (FERREIRA; BARATA, 2008a); o terceiro ciclo inclui três anos de escolaridade (sétimo, oitavo e nono anos) e está organizado curricularmente por disciplinas lecionadas por professores com formação específica nas mesmas (FERREIRA; BARATA, 2008b).

A revisão da estrutura curricular do ensino básico português foi recentemente implementada e resultou de uma nova ideologia sobre a educação, o currículo e o desenvolvimento curricular preconizada pelo Ministério da Educação e Ciência português. Essa nova estrutura curricular do ensino básico foi justificada no preâmbulo do Decreto-Lei $n^{\circ}$ 139/2012 com duas finalidades principais: "melhorar a qualidade do que se ensina e do que se aprende" e criar "uma cultura de rigor e de excelência, através da implementação de medidas no currículo dos ensinos básico e secundário". Assim, uma das alterações introduzidas refere-se à mudança na concepção de currículo formalmente assumida. Passou-se de um currículo estruturado por competências para um definido como "o conjunto de conteúdos e de objectivos que, devidamente articulados, constituem a base da organização do ensino e da avaliação do desempenho 
dos alunos" (PORTUGAL, DECRETO-LEI No 139/2012, ART. 2º PONTO 1). Esses conteúdos e objetivos constam nos programas e nas metas curriculares definidas pelo Ministério da Educação e Ciência para as disciplinas de Português, de Matemática e de Tecnologias da Informação e Comunicação. Essa concepção evidencia "uma perspetiva tyleriana de currículo como plano, uma vez que define como ponto de partida os objetivos e como ponto de chegada os resultados" (PACHECO, 2012, p. 3). São os objetivos que compõem as metas curriculares que orientam a organização do processo de ensino e de aprendizagem e a avaliação dos alunos. Consequentemente, surge uma nova forma de conceber a educação escolar e o processo de ensino e de aprendizagem, mais voltados para a aquisição de aprendizagens de conteúdos e de capacidades cognitivas nucleares por parte dos alunos do que para a criação de um pensamento complexo, que é fundamental para a vida com qualidade numa sociedade em constante mudança como a que se vive atualmente (MORIN, 1999).

Outras medidas tomadas no contexto da revisão da estrutura curricular do ensino básico foram as seguintes: "maior autonomia das escolas na gestão do currículo", pela oferta de uma disciplina de escola e pela flexibilização dos tempos de duração das aulas, desde que cumprindo o total de horas atribuídas a cada uma delas; "redução da dispersão curricular", retirando disciplinas e áreas curriculares não disciplinares que eram de frequência obrigatória - Área de Projeto, Formação Cívica e Estudo Acompanhado -, mas aumentando a carga horária nas disciplinas nucleares - Português, Matemática e Ciências (PORTUGAL, DECRETO-LEI No 139/2012, PREÂMBULO).

Em termos de organização curricular, o primeiro ciclo do ensino básico integra quatro áreas curriculares disciplinares obrigatórias: Português, Matemática, Estudo do Meio e Expressões. Já o plano curricular do segundo ciclo inclui quatro áreas disciplinares, a que correspondem diferentes disciplinas: a área das Línguas e Estudos Sociais, que integra as disciplinas de Português, Inglês e História e Geografia de Portugal; a área da Matemática e Ciências, com as disciplinas de Matemática e Ciências Naturais; a área de Educação Artística e Tecnológica, com as disciplinas de Educação Visual, Educação Tecnológica e Educação Musical. Não integrada em nenhuma área específica, surge a Educação Física e a disciplina de oferta complementar (DECRETO-LEI No 139/2012). Esta última, visando à formação integral do aluno, é de frequência obrigatória, incidirá nas áreas artísticas, culturais, científicas, de cidadania ou outras (ART. 12 ${ }^{\circ}$ PONTO 1 DO DECRETO-LEI No 139/2012). 0 terceiro ciclo, com a duração de três anos de escolaridade (sétimo, oitavo e nono anos), tem um plano de estudos de natureza disciplinar, que também está estruturado por áreas disciplinares que englobam diferentes disciplinas: a área de Português e Línguas Estrangeiras, com as disciplinas de Português, Inglês, Língua Estrangeira II (Espanhol ou Francês); a área de Ciências Humanas e Sociais, que inclui as disciplinas de História e de Geografia; a área de Matemática e Ciências Físicas e Naturais, que integra as disciplinas de Ciências Naturais e de Físico-Química; a área de Expressões e Tecnologias, onde se incluem as disciplinas de Tecnologias da Informação e Comunicação (para o sétimo e oitavo anos), de Educação Visual, de Oferta de Escola (de natureza artística ou tecnológica) e a de Educação Física (PORTUGAL, DECRETO-LEI No 139/2012).

\section{As novas orientações normativas para a avaliação das aprendizagens no ensino básico}

Foi desde 1992, com a publicação do Despacho-Normativo $\mathrm{n}^{\circ}$ 98-A/92, de 20 de junho, que a avaliação das aprendizagens dos alunos no ensino básico português assumiu uma importante função reguladora do processo de ensino e de aprendizagem. Para o cumprimento dessa função, a avaliação formativa exercia um papel considerável, já que permitia 
aos professores recolherem continuamente informações sobre as aprendizagens que os alunos estavam a fazer e sobre as dificuldades que sentiam, de forma a serem criadas as condições pedagógicas necessárias para que os alunos as ultrapassassem e, consequentemente, obtivessem sucesso escolar (BARREIRA; BOAVIDA; ARAÚJO, 2006; FERREIRA, 2007). Daí que, no referido normativo, a formativa fosse considerada a principal modalidade de avaliação no ensino básico português. Essa medida continuou com a reorganização curricular implementada com o Decreto-Lei $n^{\circ}$ 6/2001, de 18 de janeiro e, particularmente, com o Despacho-Normativo $\mathrm{n}^{\circ} 1 / 2005$, de 28 de fevereiro, que regulamentava o sistema de avaliação das aprendizagens dos alunos no ensino básico. No contexto dessas orientações legislativas, a decisão de reprovação dos alunos era tomada, preferencialmente, nos anos terminais de ciclo (quarto, sexto e nono anos), pois considerava-se que os professores deveriam tomar as medidas pedagógicas necessárias ao longo de cada ciclo que permitissem aos alunos ultrapassarem as suas dificuldades e ainda que deveria ser dado aos alunos com dificuldades o tempo que precisavam para que as pudessem ultrapassar (FERNANDES, 2007; FERREIRA, 2007).

Apesar de ter havido uma maior preocupação dos professores com os processos de aprendizagem e com a regulação dos mesmos, o fato é que, nas práticas de avaliação das aprendizagens dos alunos, a utilização de testes escritos para medir resultados de aprendizagem era preponderante. Frequentemente, a avaliação formativa era realizada pelos professores de modo informal e pouco estruturado, ou com uma natureza sumativa ${ }^{1}$ (FERNANDES, 2007; FERREIRA, 2007; PACHECO, 2012). Para isso contribuiu, segundo Pacheco (2012), a tradição dos testes na avaliação dos alunos, o currículo por disciplinas e a prescrição curricular em termos de currículo nacional.

1- A natureza sumativa da avaliação formativa decorria de os professores classificarem os testes formativos.
Recentemente, com a implementação do Decreto-Lei no 139/2012, de 5 de julho, surgiram novas orientações para a avaliação das aprendizagens no ensino básico português, quer na ideologia defendida quer nas finalidades, nas funções e nas caraterísticas de cada modalidade de avaliação. Esse normativo deixou de indicar a avaliação formativa como a principal modalidade no ensino básico, apesar de nele se referir que "a avaliação constitui um processo regulador do ensino, orientador do percurso escolar e certificador dos conhecimentos adquiridos e capacidades desenvolvidas pelo aluno" (PORTUGAL, DECRETO-LEI No 139/2012, ART. 23, PONTO 1). Nesse mesmo sentido, é referido no preâmbulo do Despacho-Normativo no 24-A/2012, de 6 de dezembro, que regulamenta a avaliação e a certificação das aprendizagens no ensino básico, que

a avaliação, constituindo-se como um processo regulador do ensino, é orientadora do percurso escolar e tem por objetivo a melhoria da qualidade do ensino através da aferição do grau de cumprimento das metas curriculares globalmente fixadas para os níveis de ensino básico.

Épor isso que, no atual sistema de avaliação das aprendizagens no ensino básico português, assume particular relevância a verificação e a certificação dos objetivos definidos nos programas e das metas curriculares estipuladas, até o momento, para as disciplinas de Português, de Matemática e de Tecnologias da Informação e Comunicação. Mestas essas que representam standards de conteúdos e resultados mensuráveis (PACHECO, 2012). Assim, no ponto 2 do artigo $23^{\circ}$ do Decreto-Lei $n^{\circ}$ 139/2012, é mencionado que a avaliação objetiva “a verifıcação dos conhecimentos adquiridos e das capacidades desenvolvidas nos alunos e a aferição do grau de cumprimento das metas curriculares globalmente fixadas" para as disciplinas do ensino básico. Prevalecendo uma perspetiva tyleriana de currículo, os objetivos e as metas curriculares 
definidas são determinantes na realização do processo de ensino e de aprendizagem e da prática da avaliação das aprendizagens dos alunos (PACHECO, 2012). A importância das metas curriculares na organização do processo de ensino e o papel da avaliação na verificação do seu cumprimento pelos alunos são visíveis quando se afirma que "a avaliação tem ainda por objetivo conhecer o estado do ensino, retificar procedimentos e reajustar o ensino das diversas disciplinas aos objetivos curriculares fixados" (PORTUGAL, DECRETO-LEI No 139/2012, ART. 23ㅇ, PONTO 4).

Se, por um lado, é dado especial relevo à verificação do cumprimento, por parte dos alunos, das metas curriculares estabelecidas, que é a condição principal para aferir o seu sucesso escolar, por outro lado, está prevista a realização da avaliação diagnóstica no início do ano letivo ou sempre que necessária. Trata-se de uma função pedagógica da avaliação que visa a diagnosticar pré-requisitos, conhecimentos prévios e interesses dos alunos pelas novas aprendizagens, originando decisões didáticas adequadas ao ponto de partida dos alunos e com as quais é iniciado o processo de ensino e de aprendizagem (HADJI, 2001; FERREIRA, 2007). Nos pontos 2 dos artigos $24^{\circ}$ e $25^{\circ}$ do Decreto-Lei $\mathrm{n}^{\circ} 139 / 2012$, essa modalidade de avaliação tem por finalidade facilitar a integração do aluno na turma e na escola, diferenciar as estratégias de ensino e de aprendizagem e possibilitar a orientação escolar e vocacional, nomeadamente encaminhando os alunos para o ensino profissional ou para percursos educativos alternativos ao ensino regular que melhor se ajustem aos seus interesses e necessidades.

Ainda se encontra prevista a avaliação formativa, que é descrita como contínua e sistemática e que é concretizada pela utilização de diversificados instrumentos de avaliação, com os quais são proporcionadas informações sobre as caraterísticas dos alunos, as aprendizagens que estão a ser realizadas e as respetivas circunstâncias em que ocorrem. Dessa avaliação decorrem ajustamentos das estratégias de ensino sempre que se revelarem necessários (PORTUGAL, DECRETO-LEI No 139/2012, ART. $24^{\circ}$, PONTO 3). A avaliação formativa assume, por isso, uma função reguladora da aprendizagem, realizada pela adaptação das estratégias e dos recursos de ensino (ALLAL, 1986; HADJI, 2001) e pelo apoio pedagógico obrigatório, no primeiro e segundo ciclos do ensino básico, ao longo da aprendizagem (PORTUGAL, DECRETO-LEI No 13972012, ART. 13º. Além disso, se o aluno terminar o ano letivo sem que tenha adquirido os conhecimentos e as capacidades definidas para o Português ou para a Matemática do ano de escolaridade que frequenta, terá de se submeter a um apoio pedagógico extraordinário, com o prolongamento do calendário escolar (PORTUGAL, DECRETO-LEI № 139/2012, ART. 25ㅇ, PONTO 5; PORTUGAL, DESPACHONORMATIVO No 24-A/2012, ART. 23, PONTO 1). Todas essas medidas de intervenção nas dificuldades de aprendizagem e de apoio pedagógico tanto podem traduzir-se - numa lógica construtivista - na individualização das estratégias de ensino que melhor se adéquem às dificuldades dos alunos e ao que as originou quanto - numa perspetiva behaviorista - na utilização de procedimentos pedagógicos corretivos ou de remediação, como a repetição de conteúdos, o treino com a realização de mais exercícios e o reforço das aprendizagens feitas (ALLAL, 1986; FERREIRA, 2007).

Todavia, a modalidade de avaliação que aparece com maiores mudanças nas orientações legislativas para a avaliação das aprendizagens no ensino básico é a sumativa, que se traduz num juízo avaliativo global sobre a aprendizagem dos alunos (PORTUGAL, DECRETO-LEI No 139/2012, ART. 26 ${ }^{\circ}$ PONTO 1). Tendo por finalidade a classificação e a certificação das aprendizagens (PORTUGAL, DECRETO-LEI No 139/2102, ART. 26ㅇ, PONTO 1), a avaliação sumativa conduz a decisões de aprovação ou de reprovação dos alunos (FERNANDES, 2007; FERREIRA, 2007). Nela, distingue-se a avaliação sumativa interna e a externa. A interna é da responsabilidade do professor da turma no 
primeiro ciclo do ensino básico e do conselho de turma no segundo e terceiro ciclos, composto pelos professores que lecionam as várias disciplinas. A referida avaliação ocorre no final de cada período e ano letivos e exprime-se por uma nota, numa escala de classificação de 1 a 5, atribuída em função do cumprimento pelos alunos dos critérios de avaliação definidos para cada disciplina e aprovados em conselho pedagógico da escola. Esses critérios são determinados tendo em conta as metas curriculares estabelecidas pelo Ministério da Educação e Ciência para as disciplinas de Português, de Matemática e de Tecnologias da Informação e Comunicação (PORTUGAL, DESPACHO-NORMATIVO No 24A/2012). No primeiro ciclo do ensino básico, a avaliação sumativa interna é descritiva em cada área curricular, com exceção de Língua Portuguesa e de Matemática, no quarto ano de escolaridade, que se exprime numa escala de 1 a 5, tal como no segundo e terceiro ciclos, mas sendo descritiva nas restantes áreas curriculares (Estudo do Meio e Expressões).

A avaliação sumativa externa é da responsabilidade do Ministério da Educação e Ciência português e concretiza-se pela realização de exames nacionais de Português e Matemática no ano terminal de cada ciclo do ensino básico (quarto, sexto e nono anos de escolaridade). A realização desses exames pelos alunos é obrigatória, já que, se não se submetem a eles, ficam impedidos de concluírem o ciclo do ensino básico que frequentam.

Os alunos dos segundo e nono anos de escolaridade realizam testes intermédios de Português e Matemática, que são elaborados pelo Gabinete de Avaliação Educacional do Ministério da Educação e Ciência (PORTUGAL, DESPACHO-NORMATIVO No 24-A/2013). Através desses testes, os professores e os alunos verificam se estão a ser realizadas as aprendizagens necessárias, com referência às metas curriculares, e as dificuldades que estão a sentir. Esses testes ainda têm por finalidade familiarizar os alunos com os instrumentos de avaliação sumativa externa (PACHECO, 2012). Assim, os testes intermédios possibilitam a regulação do processo de ensino e de aprendizagem por parte do professor e dos alunos, mas também assumem uma função de controle da administração educativa central sobre os resultados escolares e sobre o trabalho dos professores.

Apesar de, no Decreto-Lei no 139/2012, ser referido que a progressão do aluno no ensino básico é feita na lógica de ciclo, o fato é que

caso o aluno não adquira os conhecimentos predefinidos para um ano não terminal de ciclo [...], o professor titular de turma, no $1^{\circ}$ ciclo, [...] ou o conselho de turma nos $2^{\circ}$ e $3^{\circ}$ ciclos pode, a título excecional, determinar a retenção do aluno no mesmo ano de escolaridade (PORTUGAL, DECRETO-LEI No 139/2012, ART. 25ㅇ, PONTO 6).

Desse modo, na tomada de decisão de reprovação de um aluno, "nem é seguida uma lógica de ciclo nem a retenção é uma medida excepcional" (FERNANDES, 2007, p. 589). Isso porque os professores podem decidir reprovar um aluno no final de qualquer ano de escolaridade do ensino básico caso verifiquem que não adquiriu os conhecimentos e as capacidades previstas para uma dada disciplina de um ano de escolaridade. A exceção é feita para o primeiro ano de escolaridade, em que não está prevista a reprovação (PORTUGAL, DECRETO-LEI No 139/2012, ART. 25, PONTO 7). A decisão de reprovação acontece quando o aluno tem níveis iguais ou inferiores a 2 nas disciplinas de Português e de Matemática, ou quando tem esses mesmos níveis em três ou mais disciplinas (PORTUGAL, DECRETO-LEI No 139/2012; PORTUGAL DESPACHO-NORMATIVO No 24-A/2013).

\section{Uma análise do reforço dos exames nacionais no ensino básico}

As principais mudanças na avaliação das aprendizagens dos alunos do ensino básico português introduzidas com a revisão da estrutura curricular (PORTUGAL, DECRETO-LEI No 139/2012) foram a da formativa deixar de ser 
considerada a principal modalidade de avaliação e a da avaliação sumativa externa se estender a todos os ciclos desse nível de ensino. Assim, deixaram de ser realizadas as provas de avaliação aferida que, no anterior sistema de avaliação, eram feitas nos anos terminais de ciclo com a finalidade de verificar a qualidade do sistema educativo, mas sem qualquer peso na classificação e na aprovação ou reprovação dos alunos.

Até a implementação das medidas desse normativo, a avaliação externa, realizada por exames nacionais de Português e Matemática, só acontecia no último ano de escolaridade do ensino básico, isto é, no nono ano (PORTUGAL, DESPACHO-NORMATIVO № 1/2005). Todavia, com o novo sistema de avaliação, os alunos são obrigados a realizar exames dessas duas disciplinas no quarto, sexto e nono anos de escolaridade, condição necessária à conclusão dos respetivos ciclos de ensino e que tem o peso de 30\% na classificação final nas ditas disciplinas (PORTUGAL, DESPACHO-NORMATIVO No 24-A/2013). Tal peso das notas dos alunos nos exames na classificação final das duas disciplinas evitou que as mesmas voltassem a ser decisivas na aprovação ou na reprovação dos alunos, como acontecia antes de 25 de abril de 1974, data da revolução militar que marcou a transição do sistema político português para a democracia (FERNANDES, 2007).

A decisão de instituição dos exames nacionais das duas disciplinas nos anos terminais de cada ciclo foi justificada pelo Ministério da Educação e Ciência português pela necessidade de maior exigência e de rigor na avaliação dos alunos (PORTUGAL, DECRETO-LEI No 139/2012, PREÂMBULO). Porém, a avaliação por exames nacionais cumpre, segundo Fernandes (2005), funções muito mais diversificadas: a de certifıcação, porque permite comprovar aos intervenientes na educação escolar e à sociedade em geral que os alunos realizaram um conjunto de aprendizagens exigidas; a de seleção, porque os exames medem resultados de aprendizagem que originam classificações com as quais os alunos são aprovados ou reprovados; a de controle, já que, através dos exames estandardizados, os governos asseguram o cumprimento do currículo nacional em todas as escolas de cada país; a de monitorização da qualidade educativa que, associada à função de controle, é exercida pela prestação de contas por parte das escolas e dos professores sobre a educação escolar promovida; a de motivação ou desmotivação dos alunos em função dos resultados obtidos nos exames.

A decisão sobre a realização de exames das referidas disciplinas é entendida numa perspetiva neoconservadora, com a qual o currículo é diminuído às disciplinas nucleares (PACHECO, 2012), pois esses exames supostamente contribuem para

a elevação da qualidade dos padrões de ensino e de aprendizagem, para a elevação dos níveis de exigência na formação de professores e, em geral, para a melhoria do funcionamento das escolas e para um maior reconhecimento social do papel da educação no mundo do trabalho (SOUSA, 2012, p. 44-45).

Subjacente àquela decisão está também a intenção de o poder central monitorizar a qualidade e a eficácia do sistema educativo, que são aferidas pelos resultados de aprendizagem dos alunos nessas provas nacionais estandardizadas (AFONSO, 2011; FERREIRA, 2013; PACHECO, 2012).

Essa preocupação com os resultados de aprendizagem tem consequências no trabalho do professor e dos alunos, uma vez que a preparação destes para a realização dos exames se tornou a principal preocupação daqueles no exercício da sua atividade docente. Também a realização de exames finais orienta os alunos para o uso de estratégias de aprendizagem baseadas na memorização e na reprodução de informação que lhes foi previamente transmitida (ALMEIDA, 2012; FERNANDES, 2007; FERREIRA, 2013). Daí que Sousa (2012, 
p. 44) afirme que a avaliação por exames nacionais conduz ao

ensino superficial, orientado para o chamado training to the test, que absorve de forma excessiva tempo de trabalho com os alunos e sustenta o desenvolvimento de capacidades elementares, orientadas para a reprodução de conhecimento, centradas na memorização a curto prazo.

No entanto, é pelos resultados dos alunos nesses exames que o Estado português responsabiliza as escolas e os professores pela qualidade da educação escolar promovida, com consequências na avaliação da escola, no seu posicionamento num ranking nacional, estabelecido anualmente em função desses resultados dos alunos, e na imagem socialmente criada de cada escola. Cumprindo o Estado o seu papel regulador, é instituído "um sistema de avaliação independente de cada escola, que assegure a manutenção de padrões de referência à escala nacional e um mínimo de homogeneidade na gestão do currículo" (SOUSA, 2012, p. 47). Também os resultados dos alunos nos exames têm consequências na avaliação de desempenho dos docentes, já que com eles o seu trabalho é validado, sendo um indicador a considerar para a sua classificação e para a progressão na carreira profissional.

Se, por um lado, o Estado português avalia e monitoriza o sistema educativo através dos resultados dos alunos nos exames nacionais, por outro lado, assiste-se a uma certa preocupação com os processos de aprendizagem, de modo a cumprir o papel do Estado-providência. Assim, é referido no Decreto-Lei no 139/2012 que, no ensino básico, a avaliação também assume uma função reguladora do processo de ensino e de aprendizagem. Tal intenção, que visa à criação de iguais oportunidades para o sucesso escolar de todos os alunos, contraria a lógica neoliberal presente na política educativa portuguesa atual, cujos princípios tendem para o individualismo, a mercadorização da educação escolar, a livre escolha, a responsabilização pelos resultados, a competição. É devido à ambiguidade e à contradição existentes nas prescrições para a avaliação das aprendizagens naquele nível de ensino que Afonso $(2000 ; 2011)$ refere que a política educativa em Portugal tem-se caraterizado por um "neoliberalismo educacional mitigado", resultante “das pressões contraditórias exercidas pelos diferentes grupos e classes sociais que participaram, direta ou indiretamente, na definição da política educativa” (AFONSO, 2000, p. 82). Esse neoliberalismo educacional mitigado justifica-se, por um lado, por se verificar a retração do Estado português no investimento na escola pública, o qual continua, contudo, a exercer o controle sobre a qualidade da educação nela promovida, a qual é medida pelos exames em função de metas economicamente determinadas e, por essa via, ele exige a prestação de contas e a responsabilização dos professores e das escolas. Por outro lado, e contraditoriamente, o Estado português procura garantir princípios do Estado-providência, como a atribuição de uma função reguladora do processo de ensino e de aprendizagem à avaliação das aprendizagens, no sentido da criação das condições pedagógicas necessárias para que o maior número possível de alunos tenha sucesso escolar (AFONSO, 2000; 2011; FERNANDES, 2007; FERREIRA, 2007).

A contradição entre o reforço da avaliação sumativa externa e a avaliação com uma função reguladora verificada nos normativos que regulamentam a avaliação das aprendizagens no ensino básico não deveria ser vista dessa forma, mas antes como um contributo da avaliação sumativa externa para a melhoria dos resultados dos alunos. Isso seria conseguido se, à análise desses resultados, fosse associada a prática da avaliação formativa, que proporcionaria um feedback contínuo sobre as dificuldades dos alunos e as respectivas causas (FERNANDES, 2005). Nessa lógica, entendemos que a avaliação formativa e a sumativa não são antagônicas, mas antes complementares para a melhoria das aprendizagens dos alunos e das práticas de ensino dos professores. 


\section{Conclusão}

O sistema oficial de avaliação das aprendizagens no ensino básico português sofreu, desde 2012, alterações em termos ideológicos e de orientações para a prática avaliativa.

Sob influência de uma ideologia neoliberal mitigada, o atual documento normativo que regulamenta a avaliação das aprendizagens deixou de considerar a avaliação formativa como a principal modalidade de avaliação no ensino básico. Porém, essa avaliação continua prevista para o ensino básico, estando a ela associada uma função de regulação do processo de ensino e de aprendizagem que proporciona as condições pedagógicas necessárias à superação das difıculdades dos alunos. Para além da adaptação das estratégias de ensino durante as aulas, a função de regulação também é exercida pelo apoio pedagógico aos alunos do primeiro e segundo ciclos com dificuldades, de forma a evitar-se a decisão de reprovação no final de cada ano letivo.

Com vista à monitorização dos resultados de aprendizagem dos alunos e da qualidade educativa por parte do Estado português, foi alargada a avaliação sumativa externa a todos os anos terminais dos três ciclos que estruturam aquele nível de ensino. Exames esses que são obrigatórios em Português e Matemática, tendo as classificações neles obtidas pelos alunos o peso de 30\% na nota final dessas duas disciplinas. Dessa forma, as escolas e os professores são chamados a prestarem contas dos resultados dos alunos e da qualidade educativa, uma vez que, sendo os resultados nos exames tornados públicos, constituem o único indicador para o estabelecimento de rankings anuais de escolas, que originam a imagem socialmente criada de cada uma delas e que determinam o seu funcionamento. Também a aferição dos resultados dos alunos nos exames é um fator importante para a avaliação de desempenho docente e para a progressão na carreira profissional.

Apesar de os resultados na avaliação sumativa externa não serem determinantes na decisão de aprovação ou de reprovação, a obrigatoriedade da realização desses exames está a mudar as práticas letivas dos professores das duas disciplinas, que estão cada vez mais orientadas para a preparação dos alunos para um bom desempenho nos respectivos exames. Também as estratégias usadas pelos alunos na aprendizagem estão a recair na memorização de informações transmitidas e na procura de estratégias que melhor se adéquem às respostas ao tipo de questões que compõem esses exames.

Por esses motivos, consideramos que a prática da avaliação sumativa, que foi reforçada com o referido normativo, deve ser sustentada e complementada pela avaliação formativa contínua realizada durante as aulas, que possibilita o diagnóstico atempado das dificuldades de aprendizagem dos alunos e a intervenção pedagógica. Com essa articulação e complementaridade das duas funções pedagógicas da avaliação, é possivel que os alunos tenham melhores desempenhos na avaliação sumativa externa realizada no final de cada ciclo do ensino básico. 


\section{Referências}

AFONSO, Almerindo Janela. Avaliação educacional: regulação e emancipação. 2. ed. São Paulo: Cortez, 2000. 151 p.

AFONSO, Almerindo Janela. Questões polémicas no debate sobre políticas educativas contemporâneas: 0 caso da accountability baseada em testes estandardizados e rankings escolares. In: ALVES, Maria Palmira; KETELE, Jean-Marie de. (Orgs.). Do currículo à avaliação, da avaliação ao currículo. Porto: Porto Editora, 2011. p. 83-101.

AFONSO, Almerindo Janela. Mudanças no Estado-avaliador: comparativismo internacional e teoria da modernização revisitada. Revista Brasileira de Educação. v. 18, n. 53, p. 267-284, 2013.

ALMEIDA, Leandro da Silva. Avaliação dos alunos: combinando as razões e os modos. In: KARPICKE, Jeffrey; SOUSA, Hélder Diniz de; ALMEIDA, Leandro da Silva. A avaliação dos alunos. Lisboa: Fundação Manuel dos Santos, 2012. p. 71-88.

ALLAL, Linda. Estratégias de avaliação formativa: concepções psicopedagógicas e modalidades de aplicação. In: ALLAL, Linda; CARDINET, Jean; PERRENOUD, Philippe. A avaliação formativa num ensino diferenciado. Coimbra: Livraria Almedina, 1986. p. 175-196.

AMARAL, Marcelo Parreira do. Política pública educacional e sua dimensão internacional: abordagens teóricas. Educação e Pesquisa, v. 36, n. especial, p. 39-54, 2010.

BARREIRA, Carlos; BOAVIDA, João; ARAÚJO, Nuno. Avaliação formativa: novas formas de ensinar e aprender. Revista Portuguesa de Pedagogia, v. 40, n. 3, p. 95-133, 2006.

BONAMINO, Alícia; SOUSA, Sandra Zákia. Três gerações de avaliação da educação no Brasil: interfaces com o currículo da/na escola. Educação e Pesquisa, v. 38, n. 2, p. 373-388, abr./jun. 2012.

BONNIOL, Jean-Jacques; VIAL, Michel. Les modéles de l'évaluation: textes fondateurs avec commentaires. Bruxelles: De Boeck Université, 1997. 368 p.

DALE, Rale. Globalização e educação: demonstrando a existência de uma "cultura educacional mundial comum" ou localizando uma "agenda globalmente estruturada para a educação"? Educação \& Sociedade, Campinas, v. 25, n. 87, p. 423-460, maio/ ago. 2004.

FERNANDES, Domingos. Avaliação das aprendizagens: desafios às teorias, práticas e políticas. Lisboa: Texto, 2005. 160 p.

FERNANDES, Domingos. A avaliação das aprendizagens no Sistema Educativo Português. Educação e Pesquisa, São Paulo, v. 33, n. 3, p. 581-600, set./dez. 2007.

FERREIRA, Carlos Alberto. A avaliação no quotidiano da sala de aula. Porto: Porto Editora, 2007. 239 p.

FERREIRA, Carlos Alberto. Os exames na avaliação da aprendizagem: entre o rigor e a seleção? In: FERREIRA, Carlos Alberto et al. (Orgs.). JORNADAS PEDAGÓGICAS - 0 PROFESSOR FAZ A DIFERENÇA NO DESEMPENHO ESCOLAR, 2., Trás-os-Montes e Alto Douro, 12, 19 e 26 de outubro de 2013. Atas... Vila Real: Universidade de Trás-os-Montes e Alto Douro, 2013. p. 97-110.

FERREIRA, Carlos Alberto. Uma leitura das práticas de avaliação formativa com a utilização das fichas/testes formativos. In: MOREIRA, Antonio Flávio et al. (Orgs.). COLÓQUIO LUSO-BRASILEIRO: GLOBALIZAÇÃO E (DES)IGUALDADES: Os desafios curriculares, 3., Braga, 2006. Actas... Braga: Centro de Investigação em Educação da Universidade do Minho, 2006. p. 127-139.

FERREIRA, José Brites; BARATA, C. Ensino básico: 2. ciclo. In: PACHECO, José Augusto. (Org.). Organização curricular portuguesa. Porto: Porto Editora, 2008a. p. 129-187.

FERREIRA, José Brites; BARATA, C. Ensino básico: 3. ciclo. In: PACHECO, José Augusto. (Org.). Organização curricular portuguesa. Porto: Porto Editora, 2008b. p. 191-220.

HADJI, Charles. Avaliação desmistificada. Tradução de Patrícia C. Ramos. Porto Alegre: Artmed, 2001. 136 p. 
LAVEAULT, Dany; GRÉGOIRE, Jacques. Introdução às teorias dos testes em ciências humanas. Porto: Porto Editora, 2002. $335 \mathrm{p}$.

MORIN, Edgar. La tête bien faite. Paris: Seuil, 1999. 154 p.

PACHECO, José Augusto. Discursos e lugares das competências em contextos de educação e formação. Porto: Porto Editora, 2011. 128 p.

PACHECO, José Augusto. Contextos e características do neoliberalismo em educação. In: PACHECO, José Augusto (Org.). Políticas educativas: 0 neoliberalismo em educação. Porto: Porto Editora, 2000. p. 7-20.

PACHECO, José Augusto. Avaliação das aprendizagens: políticas formativas e práticas sumativas. In: Encontros de Educação, Funchal, 10 e 11 de fevereiro de 2012. Encontros... Funchal: Secretaria da Educação do Governo Regional da Madeira, 2012. p. 1-9.

PEREIRA, N. Ensino primário/ensino básico: 1. ciclo. In: PACHECO, José Augusto. (Org.). Organização curricular portuguesa. Porto: Porto Editora, 2008. p. 85-128.

PERRENOUD, Philippe. L'évaluation des élèves. De la fabrication de l'excellence à la régulation des apprentissages: entre deux logiques. Bruxelles: De Boeck Université, 1998. 219 p.

PORTUGAL. Decreto-lei nº 6/2001, de 18 de janeiro. Reorganização curricular do ensino básico.

PORTUGAL. Decreto-lei n 139/2012, de 5 de julho. Revisão da estrutura curricular dos ensinos básico e secundário portugueses. PORTUGAL. Despacho-normativo nº 1/2005, de 28 de fevereiro. Sistema de avaliação das aprendizagens no ensino básico.

PORTUGAL. Despacho-normativo nº 24-A/2012, de 6 de dezembro. Regulamenta a certificação de conhecimentos e capacidades desenvolvidas pelos alunos do ensino básico.

PORTUGAL. Lei nº 46/86, de 14 de outubro. Lei de bases do sistema educativo português.

SANTOMÉ, Jungo Torres. 0 professorado na época do neoliberalismo: aspetos sociopolíticos do seu trabalho. In PACHECO, José Augusto (Org.). Políticas educativas: o neoliberalismo em educação. Porto: Porto Editora, 2000. p. 67-90.

SOUSA, Hélder Diniz de. Exames nacionais: instrumentos de regulação de boas práticas de ensino e de aprendizagem? In: KARPICKE, Jeffrey; SOUSA, Hélder Diniz de; ALMEIDA, Leandro da Silva. A avaliação dos alunos. Lisboa: Fundação Manuel dos Santos, 2012. p. 41-69.

VALADARES, Jorge; GRAÇA, Margarida. Avaliando para melhorar a aprendizagem. Lisboa: Plátano, 1998. 211 p.

Submetido em: 13.04.2014

Aprovado em: 12.08.2014

Carlos Alberto Ferreira é professor da Universidade de Trás-os-Montes e Alto Douro, investigador do Centro de Investigação em Educação da Universidade do Minho. 